\title{
More than meets the eye: a comprehensive review of blepharoptosis
}

\author{
Matthew T. Floyd ${ }^{1}$, Hee Joon Kim² \\ 'Department of Ophthalmology, Emory University, Atlanta, GA 30322, USA. \\ ${ }^{2}$ Department of Ophthalmology, Section of Oculoplastics, Orbital and Cosmetic Surgery, Emory University, Atlanta, GA 30322,
} USA.

Correspondence to: Dr. Hee Joon Kim, Department of Ophthalmology, Section of Oculoplastics, Orbital and Cosmetic Surgery, Emory University, 1365B Clifton RD, NE, Atlanta, GA 30322, USA. E-mail: hee.j.kim@emory.edu

How to cite this article: Floyd MT, Kim HJ. More than meets the eye: a comprehensive review of blepharoptosis. Plast Aesthet Res 2021;8:1. http://dx.doi.org/10.20517/2347-9264.2020.110

Received: 15 May 2020 First Decision: 22 Sep 2020 Revised: 10 Oct 2020 Accepted: 24 Nov 2020 Published: 8 Jan 2021

Academic Editor: Raúl González-García Copy Editor: Cai-Hong Wang Production Editor: Jing Yu

\begin{abstract}
Blepharoptosis is present when the upper eyelid is lower than its normal anatomic position in primary gaze. This is secondary to a neuromuscular imbalance with weakening of the upper eyelid retractors in relation to the protractors. As the degree of ptosis worsens, significant functional and cosmetic concerns often arise. To adequately address these concerns, ptosis is divided into categories based on the underlying pathogenesis: aponeurotic, myogenic, neurogenic, mechanical, or traumatic. Within these categories, it is important to determine if the ptosis is congenital or acquired as diagnostic and therapeutic approaches often vary between these two distinctions. The goal of this review is to summarize the classification, evaluation, management, and potential pitfalls of both acquired and congenital ptosis.
\end{abstract}

Keywords: Ptosis, blepharoptosis, congenital, aponeurotic, neurogenic, myogenic, traumatic, mechanical

\section{INTRODUCTION}

Blepharoptosis, commonly referred to as ptosis, is present when the upper eyelid is lower than its normal anatomic position in primary gaze. The term is derived from the Greek expression blepharon "eyelid" and ptōsis "act of falling" corneal limbus with ptosis being classified as mild $(1-2 \mathrm{~mm})$, moderate $(3-4 \mathrm{~mm})$, or severe $(>4 \mathrm{~mm})^{[3]}$. As the degree of ptosis worsens, significant functional and cosmetic concerns often arise. Blepharoptosis

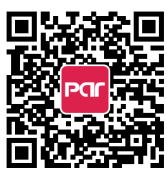


is generally classified into categories based on the underlying pathogenesis: aponeurotic, myogenic, neurogenic, mechanical, and traumatic ${ }^{[4]}$. Within these classifications, there are further subdivisions to aid diagnosis and management based on whether the ptosis is congenital or acquired, unilateral or bilateral, isolated or syndromic, or symptomatically driven by cosmetic or functional deficits. The goal of this review is to summarize the classification, evaluation, management, and potential pitfalls of both acquired and congenital ptosis.

\section{ANATOMY}

Ptosis often serves as a harbinger of underlying pathology along the neuromuscular pathway of the eyelid retractors. To differentiate the many etiologies of ptosis, an intimate knowledge of this pathway is necessary. Elevation of the upper eyelid is a complex process accomplished by three different retractors, each with its own distinct innervation. Any direct or indirect impact on these muscles can result in blepharoptosis ${ }^{[5]}$.

Levator palpebrae superioris, commonly referred to as the levator, is a striated muscle that serves as the primary retractor of the upper eyelid. The levator originates from the lesser wing of the sphenoid above the annulus of Zinn and travels anteriorly to the superior transverse ligament (Whitnall's ligament) that functions as a check ligament transferring the anterior-posterior vector of force to a superior-inferior vector which functions to lift the eyelid. The levator muscle belly tapers to the levator aponeurosis that divides into an anterior and posterior portion just superior to the tarsal border. The anterior portion inserts on the pretarsal orbicularis, forming the eyelid crease, while the posterior portion inserts on the lower anterior surface of the tarsus. The levator muscle belly is $40 \mathrm{~mm}$ in length with the levator aponeurosis adding an additional $14-20 \mathrm{~mm}^{[6]}$. The levator is innervated by a central common oculomotor nerve (CN-III) subnucleus located in the rostral midbrain. After exiting the brainstem, CN-III travels between the posterior cerebral and superior cerebellar arteries prior to entering the roof of the cavernous sinus where it receives sympathetic fibers from the internal carotid artery plexus. $\mathrm{CN}$-III then passes through the oculomotor foramen before branching into the superior division of the oculomotor nerve and inserting on the inferior surface of the levator ${ }^{[7]}$.

Müller's muscle is a sympathetically innervated smooth muscle that serves as an accessory retractor of the upper eyelid. It originates underneath the levator aponeurosis $12-13 \mathrm{~mm}$ above the upper tarsal margin and inserts at the superior tarsal border. An important surgical landmark is the peripheral arterial arcade that can be found running between Müller's muscle and the levator aponeurosis. Müller's muscle is responsible for about $2 \mathrm{~mm}$ of eyelid retraction ${ }^{[7]}$.

The frontalis muscle, innervated by the facial nerve, is the weakest of the upper eyelid retractors. It indirectly raises the upper eyelid $2 \mathrm{~mm}$ or less by lifting the eyebrows and does not utilize a bony origin or insertion.

\section{CLASSIFICATION}

Blepharoptosis is subject to many classification systems that represent the diagnostic, prognostic, and therapeutic facets of its various diverse presentations. While each system holds merit in patient counseling or surgical management, this review will discuss classifications based on the underlying pathogenesis: aponeurotic, myogenic, neurogenic, mechanical, and traumatic ${ }^{[4]}$.

\section{Aponeurotic ptosis}

Aponeurotic or "senile" ptosis is the most commonly encountered form of ptosis in the United States, accounting for approximately $60 \%$ of ptosis referrals ${ }^{[8]}$. The levator palpebrae superioris undergoes a slow, chronic disinsertion from the tarsal plate as a result of cumulative age-related degeneration and gravity. 
This is frequently described by the patient as a gradual, bilateral process but is often asymmetric. While the inciting stimulus is often involutional changes, certain insults can hasten this degenerative process. Intraocular surgery (eyelid speculum), frequent digital manipulation of the eyelids (allergies, blepharitis, compulsions, long-term contact lens use), and chronic eyelid inflammation have been shown to promote aponeurotic ptosis formation ${ }^{[9-13]}$. The levator function is often within the normal range $(>10 \mathrm{~mm})$ even in the setting of moderate to severe ptosis. Examination can show a well-formed lid crease that is higher than its normal anatomic position secondary to dehiscence of the anterior portion of the levator aponeurosis from the pretarsal orbicularis. The affected eyelid will also remain ptotic in all gazes including downgaze, which explains the difficulty reading that many patients with aponeurotic ptosis experience. Although rare, congenital aponeurotic ptosis can occur when the distal levator aponeurosis fails to attach to the anterior surface of the tarsus around the 10 th week of embryonic development ${ }^{[14]}$. The levator function remains grossly preserved with variable heights of a well-formed lid crease. Of important distinction, congenital aponeurotic blepharoptosis can manifest a significant amount of ptosis (3-4 $\mathrm{mm}$ ) without lid lag on downgaze as is commonly seen in many other dystrophic forms of congenital ptosis ${ }^{[14]}$.

\section{Myogenic ptosis}

Myogenic ptosis stems from the presence of a myopathy, a disorder primarily of the levator palpebrae superioris. Myogenic ptosis can present as congenital or acquired, acute or chronic, unilateral or bilateral, and isolated or syndromic. We will discuss congenital $v s$. acquired etiologies as myogenic ptosis is reportedly the most common form of congenital ptosis in oculoplastic practice in both the United States and the United Kingdom ${ }^{[15,16]}$.

Isolated congenital myogenic ptosis in certain studies comprised $74 \%-76 \%$ of ptosis cases in the pediatric age group ${ }^{[15,16]}$. The classic presentation is a non-progressive ptosis that is unilateral in $75 \%$ of cases and asymmetric when bilateral ${ }^{[17]}$. Recent histopathological studies of isolated congenital myogenic ptosis have shown a dysgenesis of the anterior portion of the levator palpebrae superioris with striated muscle fiber loss and loose connective tissue proliferation, which impairs the ability of the levator to contract or relax ${ }^{[18-20]}$. Examination findings are reflective of the histopathology where levator function is markedly decreased, and the upper eyelid crease is poorly formed or absent in severe cases. In contrast to congenital aponeurotic ptosis, there is often significant lid lag in downgaze (von Graefe's sign) with baseline lagophthalmos in some cases. Concomitant dysgenesis of the superior rectus can be seen in $5 \%$ of cases leading to a poor Bell's phenomenon and monocular elevation deficiency strabismus ${ }^{[17]}$.

Blepharophimosis ptosis epicanthus inversus syndrome (BPES) is a sporadic or autosomal dominant (chromosome 3q22) inherited disorder that represents another clinically significant form of congenital myogenic ptosis. The syndrome classically entails horizontal and vertical shortening of the eyelids with epicanthus inversus. Additional features often include hypertelorism and/or telecanthus, hypoplasia of the superior orbital rim, hypoplasia of the nasal bridge, and/or ear deformities. Histopathologic features of BPES demonstrate striated muscle fiber atrophy and fat infiltration supportive of levator dysgenesis. The resulting ptosis is usually bilateral, symmetric, and severe with levator function $<4 \mathrm{~mm}$. Examination findings classically demonstrate a poorly formed eyelid crease, lid lag in downgaze, anomalous head positioning, and severe frontalis over-action to clear the visual axis ${ }^{[2,22]}$. Correction with a frontalis sling is often required to account for poor levator function.

Acquired myogenic ptosis includes primary inherited myopathies with a chronic, progressive decline in levator function as well as secondary myopathies that are associated with systemic conditions. Primary inherited myopathies are comprised of the mitochondrial and autosomal dominant/recessive inherited disorders listed in Table 1. Chronic progressive external ophthalmoplegia (CPEO) represents the most prevalent primary inherited myopathy ${ }^{[8,23]}$. These affected individuals typically present at 30-40 years of age 


\begin{tabular}{ll}
\hline Myopathy & \multicolumn{1}{c}{ Pattern of inheritance } \\
\hline Chronic progressive external ophthalmoplegia & Mitochondrial \\
Kearns-Sayre syndrome & Mitochondrial \\
Mitochondrial encephalopathy lactic acidosis stroke-like episodes & Mitochondrial \\
Myotonic dystrophy & Autosomal dominant DMPK gene mutation \\
Oculopharyngeal muscular dystrophy & Autosomal dominant PABPN1 gene mutation \\
Oculopharyngodistal myopathy & Autosomal dominant/recessive LRP12 gene mutation \\
Facioscapulohumeral muscular dystrophy & Autosomal dominant chromosome 4-D4Z4 deletion \\
\hline
\end{tabular}

with bilateral ptosis and ophthalmoplegia, which can accompany sensorineural hearing loss and dysphagia. Despite often severe extraocular motility deficits, patients can frequently present without diplopia. A significant distinction should be made for Kearns-Sayre syndrome (KSS), which mimics CPEO with the exceptions of onset before 20 years of age, bilateral pigmentary retinopathy, cardiovascular conduction deficits, CSF protein $>1 \mathrm{~g} / \mathrm{L}$ and cerebellar ataxia. Both CPEO and KSS develop mitochondrial DNA deletions that impair oxidative phosphorylation as an essential process for the metabolic demands of active muscle. Diagnostic muscle biopsy shows "ragged red fibers" with Gomori trichrome staining and can often be gathered from the orbicularis muscle during ptosis repair. Oculopharyngeal muscular dystrophy (OPMD) and myotonic dystrophy (MD) also develop adult onset progressive ptosis and external ophthalmoplegia. OPMD is diagnosed via autosomal dominant PABPN1 gene mutation with systemic dysphagia and proximal limb weakness, while MD is diagnosed via DMPK gene mutation and clinical findings of cardiomyopathy, frontal balding, and testicular atrophy ${ }^{[23]}$. Examination findings for these conditions show bilateral, symmetric, and moderately to severely decreased levator function with the ptotic eyelid often impeding the central visual axis. Surgery is typically deferred until it involves the central visual axis, given that there is a high incidence of recurrence despite operative intervention ${ }^{[24]}$. Secondary myopathies that have been reported to induce myogenic ptosis include heavy metal toxicity, periocular steroid injections, and HIV HAART therapy ${ }^{[25-27]}$.

\section{Neurogenic ptosis}

Neurogenic ptosis is an uncommon cause of ptosis that can signal serious underlying systemic conditions. Ptosis represented by this classification is secondary to an innervational deficit of the upper eyelid retractors. Involved neural pathways primarily include the oculomotor nerve (CN-III) and the sympathetic nervous system. Studies estimating the prevalence of neurogenic ptosis in oculoplastic practice have found that it accounts for $5 \%-15 \%$ of ptosis referrals depending on the featured age demographic ${ }^{[8,15,28]}$.

Acquired and congenital neurogenic ptosis is commonly caused by an injury to CN-III as the neural conduit to the levator palpebrae superioris. The most commonly acquired CN-III insult is microvascular ischemia, driven by the vasculopathic risk factors of diabetes, hypertension, hyperlipidemia, and smoking ${ }^{[29]}$. However, serious etiologies such as a posterior communicating (PCOM) aneurysm, giant cell arteritis, trauma, or malignancy (perineural invasion of squamous cell carcinoma) should be considered in the appropriate clinical setting ${ }^{[30]}$. Patients commonly present with acute onset diplopia and ptosis with classic CN-III palsy on examination findings of ptosis, pupillary mydriasis, and ocular motility deficits. Although neuroimaging in pupil sparing CN-III palsies is subject to debate, urgent CTA/MRA evaluation for a PCOM aneurysm should be pursued in the presence of pathologic mydriasis. Published studies estimate that only $25 \%$ of microvascular CN-III palsies involve the pupil ${ }^{[31,32]}$. Likewise, impairment of pupillary function has been found in $86 \%-95 \%$ of patients with PCOM aneurysms as parasympathetic innervation runs superficially along $\mathrm{CN}-\mathrm{III}^{[33]}$. Examination of the eyelids often shows moderate to severe unilateral ptosis with varying levator function based on whether the neuropathy is partial or complete. Insults to the oculomotor nucleus in the midbrain can produce an acute bilateral ptosis via involvement of the caudal central subnucleus that supplies innervation to bilateral levator palpebrae superioris muscles. 
Table 2. Horner syndrome pathology

\begin{tabular}{ll}
\hline Location & \multicolumn{1}{c}{ Pathology } \\
\hline First-order lesions: posterolateral & Cervical disc disease \\
hypothalamus to C8-T2 in spinal column & Syringomyelia \\
& Cerebrovascular accident \\
& Hemorrhage \\
& Demyelination \\
& Neoplasia \\
& Neuroblastoma \\
Second-order lesions: C8-T2 in spinal & Thyroid malignancy \\
column to superior cervical ganglion & Brachial plexus injury \\
& Pancoast lung tumor \\
& Thoracic aortic aneurysm \\
& latrogenic \\
Third-order lesions: superior cervical & Carotid artery dissection \\
ganglion to Muller's muscle & Cavernous sinus pathology \\
& Cluster headache \\
& SUNCT headache \\
& Otitis media \\
\hline
\end{tabular}

Spontaneous recovery is expected within 3 months in $70 \%$ of microvascular nerve palsies; however, CN-III damage due to trauma or compression may require surgical intervention to achieve ptosis resolution ${ }^{[29,34]}$. Blepharoptosis correction in congenital CN-III palsies can represent a particularly challenging management situation with exposure keratitis and amblyopia often contributing to a disappointing visual prognosis after frontalis sling repair ${ }^{[35,36]}$.

Marcus Gunn jaw-winking (MGJW) syndrome represents the most common form of congenital neurogenic ptosis secondary to synkinesis. Synkinesis is a process where voluntary muscle activation triggers a simultaneous involuntary contraction of muscles that share the same or different innervation. Aberrant connections form between CN-III supplying the levator palpebrae superioris and CN-V supplying the muscles of mastication. This can be observed during nursing as elevation of the unilateral, ptotic eyelid occurs during sucking, swallowing, or chewing. The most common jaw movement that initiates elevation of the ptotic eyelid is lateral mandibular movement to the contralateral side via the external pterygoid. If the ptosis becomes visually significant, denervation and/or surgical correction can be considered.

Congenital cranial dysinnervation disorders (CCDDs) represent a rare etiology of congenital neurogenic ptosis that occurs as a result of aberrant innervation of facial and ocular musculature. This generally arises from dysgenesis or agenesis of the cranial nerve nuclei or their axonal connections with many having suspected or confirmed genetic etiology. Congenital fibrosis of the extraocular muscles (CFEOM), Duane retraction syndrome (DRS), Möbius syndrome, and monocular elevation deficiency can result in congenital ptosis with varying degrees of neurogenic dysinnervation ${ }^{[37,38]}$.

Horner syndrome (HS) occurs secondary to a disruption in the sympathetic nervous system that extends from the posterolateral hypothalamus to the iris dilator muscle and Müller's muscle. Incidence in two oculoplastic referral centers found that HS represented $1 \%-2 \%$ of new ptosis presentations ${ }^{[8,16,28]}$. As an acquired condition, HS manifests as a mild 1-2 mm neurogenic ptosis, pupillary miosis, and/or anhidrosis that are ipsilateral to the location of the sympathetic damage. Congenital HS can further demonstrate decreased iris pigmentation from the absence of a sympathetic trophic effect on iris melanocytes. Given the significant length that the sympathetic nervous system must travel to innervate the eye, there are many different conditions that can present as a HS. Etiologies seen in Table 2 are classified as first-, second-, and third-order on the basis of the location of the insult in the sympathetic neural pathway. Pharmacological drop testing in the office can localize and/or diagnose HS. Cocaine drops at 4 or $10 \%$ concentration will fail to dilate the pupil if HS is present, whereas 0.5 or $1 \%$ apraclonidine drops will dilate the pupil if HS is confirmed. Further localization of HS to first- or second-order etiologies can be accomplished using 
$1 \%$ hydroxyamphetamine. Full dilation occurs in an intact sympathetic nervous system or preganglionic HS, but poor or no dilation occurs in a postganglionic Horner ${ }^{[39]}$. Drop testing can be a useful clinical adjunct, but this does not replace the need for MRI evaluation of the brain, spine, and thorax to exclude more sinister pathologies. Oculosympathetic imaging can allow for timely detection of potentially lifethreatening carotid artery dissection, the most common identifiable etiology of acquired $\mathrm{HS}^{[40,41]}$. Once the underlying sympathetic lesion has been addressed, evaluation for ptosis repair via traditional levator advancement, Müller's muscle-conjunctiva resection, or Fasanella-Servat procedure can occur ${ }^{[42]}$.

Myasthenia gravis (MG), an acquired autoimmune condition, occurs when acetylcholine receptor autoantibodies disrupt post-synaptic neuromuscular junctions, and hence, it can also be seen classified as a myogenic ptosis. Acquired ptosis is the most common ocular sign in MG with unilateral, bilateral, or alternating laterality and variable levator function accompanying systemic manifestations such as variable proximal motor weakness, dysphagia, and dysarthria. Examinations findings include Cogan's lid twitch, fatigue with prolonged upgaze, incomitant strabismus, and external ophthalmoplegia. Ptosis can temporarily improve with edrophonium/pyridostigmine testing (acetylcholinesterase inhibitor) or ice pack testing (slowed enzymatic activity of acetylcholinesterase). Surgical ptosis correction requires meticulous selection of candidates that have experienced medical therapy failure or have been stable on medical therapy for 3-4 years ${ }^{[43]}$. With external levator advancement, $80 \%-90 \%$ of patients can achieve increased lid height ${ }^{[44,45]}$. However, preoperative counseling remains paramount as objective improvement has been shown to not always confer subjective satisfaction ${ }^{[4]}$. While MG is often acquired as a young adult, there are rare instances where a similar presentation of congenital myasthenic syndrome can cause congenital neurogenic ptosis in a newborn. The pathogenesis of these two similar clinical phenotypes is different with congenital myasthenic syndrome occurring as a result of a genetically inherited protein abnormality affecting post-synaptic acetylcholine receptors. This can be managed medically with anticholinesterase inhibitors or via a potassium channel inhibitor, such as 3,4-diaminopyridine ${ }^{[46]}$.

Botulinum toxin can also inadvertently cause an acquired neurogenic ptosis when injected in the periorbital tissue. This can occur in the setting of periocular injections that spread locally into the levator. In contrast to MG auto-antibodies that affect the post-synaptic neuromuscular junction, botulinum toxin and its derivatives work to block release of acetylcholine from pre-synaptic nerve terminals via cleavage of docking proteins. This neurogenic ptosis effect is temporary, often occurring 2-10 days after treatment and resolving within 2-4 weeks ${ }^{[47,48]}$.

A number of supranuclear conditions can result in acquired neurogenic ptosis including cerebrovascular accidents (especially right hemispheric lesions and large infarctions), multiple sclerosis, traumatic brain injury, Wernicke's encephalopathy, and meningitis ${ }^{[3,49-52]}$.

\section{Mechanical ptosis}

Mechanical ptosis results from the inability of the upper eyelid to retract secondary to mass effect preventing retraction under the orbital rim, cicatricial changes of the surrounding skin/conjunctiva, or mass effect generating a downward force that cannot be overcome by the eyelid retractors. This is most commonly acquired in the adult population via involutional brow ptosis, dermatochalasis, and large chalazia causing mildly decreased levator excursion and mild to moderate ptosis. Acquired cicatricial skin changes and symblepharon formation can also prevent the eyelid from fully opening as a secondary manifestation of ocular cicatricial pemphigoid and Stevens-Johnson syndrome ${ }^{[\beta]}$. As opposed to the aforementioned etiologies that likely require surgical correction, many causes of mechanical ptosis can resolve with conservative therapy. Idiopathic orbital inflammation, postoperative/traumatic edema, and eyelid hematomas often resolve with medical therapy or close observation. Failure of the mechanical ptosis to resolve or suspicion for malignancy should prompt the clinician to pursue an orbital MRI with 
fat suppression and gadolinium contrast for better characterization ${ }^{[17]}$. Primary and metastatic eyelid malignancies such as Merkel cell carcinoma, sebaceous cell carcinoma, scirrhous breast cancer, small cell lung carcinoma, prostate carcinoma, renal cell carcinoma, medullary thyroid carcinoma, and lymphoma have all been documented to initially present to the clinical setting under the guise of ptosis $^{[53-57]}$.

Mechanical ptosis also holds clinical importance in the pediatric population. Infectious pre-septal and post-septal cellulitis is a frequent oculoplastics consultation that presents with significant ptosis. While this condition often resolves with antibiotic therapy, potentially amblyogenic ptosis has been shown to persist in $1 \%-2 \%$ of patients over 7 months after resolution of the acute infectious process ${ }^{[58]}$. Benign malignancies of the eyelid such as capillary hemangiomas and plexiform neurofibromas (neurofibromatosis type I) can also induce ptosis and amblyopia in vulnerable infants. Plexiform neurofibromas manifest as a lateral "S-shaped" ptosis and are accompanied by thickening of the eyelid. Studies addressing plexiform neurofibromas of the eyelid have demonstrated refractive or deprivation amblyopia in up to $43 \%$ of children evaluated ${ }^{[59,60]}$. Similar to adults, an orbital MRI with fat suppression and gadolinium contrast should be pursued for better characterization of any eyelid mass, as more sinister neuroblastoma or rhabdomyosarcoma can also occur in young children ${ }^{[61,62]}$. Although exceedingly rare, hidrocystomas, encephaloceles, and meningoencephaloceles can present as congenital mechanical ptosis and often require surgical excision ${ }^{[63-65]}$.

\section{Traumatic ptosis}

Traumatic ptosis occurs in the setting of damage to the levator palpebrae superioris, levator aponeurosis, Müller's muscle, frontalis muscle, or the innervation that supplies these upper eyelid retractors. The mechanism of injury can include direct or indirect muscular injury, neurotoxins, mass effect from scars or foreign bodies, iatrogenic damage, cranial nerve damage, or cicatricial tethering of the skin. This classification represents a heterogenous collection that combines aspects of aponeurotic, myogenic, neurogenic, and mechanical ptosis with each case. The levator function, marginal reflex distance, severity of ptosis, and examination findings also reflect this variability. When addressing traumatic ptosis, a period of 3 months or more should be allowed for observation and spontaneous recovery from traumatic edema and hemorrhage. While a significant amount of traumatic ptosis resolves during this time, surgical intervention is often necessary to address functional deficits. Jacobs et al ${ }^{[6]}$ showed that patients can benefit from tailored surgical approaches based on the distinct subtype of traumatic ptosis encountered (i.e., myogenic, aponeurotic, mechanical, neurogenic). Of note, rare cases of post-traumatic CN-III neurogenic ptosis can develop remote synkinesis involving the levator palpebrae superioris years after the initial injury. While traumatic ptosis by definition is not a dysgenesis, congenital traumatic ptosis has been shown to occur secondary to birth trauma ${ }^{[3]}$.

\section{Pseudoptosis}

Pseudoptosis must also be considered when evaluating ptosis referrals. The deceptive appearance of a drooping eyelid with intact levator, Müller's, and frontalis muscle function should be differentiated from true ptosis by careful clinicians. Pseudoptosis is most commonly caused by dermatochalasis where the upper eyelid skin overhangs the lashes giving a false perception of lower eyelid station ${ }^{[67]}$. Additional etiologies of pseudoptosis include microphthlamos, enophthalmos, phthisis bulbi, voluntary ptosis, and synkinesis ${ }^{[68,69]}$.

Synkinesis represents an uncommon, but clinically relevant etiology of acquired pseudoptosis. It can cause pseudoptosis via aberrant regeneration of $\mathrm{CN}-\mathrm{VII}$ and $\mathrm{CN}-\mathrm{III}^{[70]}$. Aberrant regeneration of CN-VII after Bell's palsy, surgical injury, and trauma can lead to increased tone of the orbicularis oculi. This causes a narrowing of the vertical palpebral fissure and the appearance of ptosis, but levator function remains intact. Aberrant regeneration of CN-III may occur secondary to compression or trauma but does not occur with microvascular ischemia. It is presumed that this is due to the lack of endoneurial disruption with 
microvascular ischemia. Although not confirmed, it is proposed that traumatic or compressive endoneurial disruption allows for misdirection of regenerating axons and resulting synkinesis ${ }^{[71-73]}$. Examination of the patient often shows true ptosis in the affected eye as a sequela of the original CN-III palsy. Upon activation of the synkinetic innervation, most commonly in adduction or infraduction (pseudo-von Graefe sign), the affected eyelid becomes retracted and the contralateral eyelid can develop pseudoptosis as a result of Hering's law of equal innervation. Surgical correction of the eyelid with true ptosis can be pursued with appropriate preoperative patient counseling, given the challenging relationship between the extraocular muscles and the aberrantly innervated levator palpebrae superioris ${ }^{[7]]}$.

\section{EVALUATION}

To differentiate the many etiologies of ptosis discussed above, a thorough clinical evaluation is warranted. Special attention must be given towards the patient's subjective history, objective examination, and ancillary testing.

\section{History}

Patients that present for ptosis evaluation often report complaints that are both functional and cosmetic. Functional ptosis can cause eyelid fatigue, headaches from frontalis recruitment, chin-up head tilt, neck pain, difficulty driving or reading, and decreased peripheral vision ${ }^{[75]}$. Cosmetic complaints often focus on achieving facial symmetry as the perception of ptosis severity can be exacerbated by asymmetric eyelid features. Most cosmetic evaluations seek to achieve an appearance reflective of the patient's own youth, thus clinical photographs of the eyelid crease and contour as a younger adult can be helpful in achieving an optimal surgical plan. While patients may not volunteer such additional details, pointed questioning should assess for diplopia, diurnal variation, pain, exacerbating/alleviating factors, trouble swallowing, trouble speaking, or recent onset of other neurologic symptoms. A thorough ocular and medical history of the patient and family should be documented with attention to important factors such as dry eye symptoms, thyroid eye disease, bleeding diatheses, cerebrovascular events, prior eyelid surgeries, and prior trauma (eyes, head, or neck) that can influence surgical planning. Use of anticoagulants, aspirin, nonsteroidal antiinflammatory drugs, vitamin $\mathrm{E}$, and gingko and other herbal medications should also be documented ${ }^{[76]}$.

When evaluating adults and particularly pediatric patients, the age of onset and the duration of ptosis is an important inquiry. Acute onset ptosis in young patients can indicate a more serious underlying problem, while chronic ptosis can carry an increased risk of amblyogenic visual loss. Cosmetic and social concerns are also of great importance in the pediatric population where patient are perceived to be more intelligent, trustworthy, and happy following their ptosis repair ${ }^{[77]}$.

\section{Clinical examination}

A complete ophthalmic and neurologic examination is warranted to properly evaluate a patient with ptosis. Systemic motor weakness, anomalous head positioning, facial asymmetry, synkinesis, strabismus, abnormal speech, and difficulty swallowing can be passively observed while taking an oral history from the patient. Frontalis excursion with elevated eyebrows should be noted for every patient as this must be neutralized to ensure correct assessment of levator and Müller's muscle function.

Best corrected visual acuity with refraction, careful pupil examination (anisocoria, afferent pupillary defect), and intraocular pressure should be recorded. Strabismus should be evaluated in the cardinal gazes. Ductions and versions should be performed with active observation for signs such as Cogan's lid twitch (overshooting of the upper lid from upgaze to downgaze), von Graefe's sign (lagging of the upper lid on downgaze), gaze-evoked pain, and supraduction limitation. Fatigable upgaze should be evaluated and supplemented with an ice test if high level of suspicion for MG exists. Palpation of the eyelids, lacrimal gland, and orbit should be performed with further assessment via exophthalmometer if proptosis, 
resistance to retropulsion, or enophthalmos is suspected. Evaluation of Bell's phenomenon, orbicularis function, and corneal sensation should be performed if poor corneal coverage is present. A thorough slit lamp examination should be conducted with attention towards the ocular surface health (blepharitis, meibomian gland disease, low tear meniscus, and increased tear break up time). Dilated fundus exam should be documented to assess for associated lens opacities MD, retinopathy (Kearns-Sayre syndrome), or fundus cyclotorsion. However, this should be delayed until a full eyelid examination has been completed, as dilating eye drops (phenylephrine) can temporarily raise the eyelid position. A general survey of the patient's visual field should be attempted via confrontation or a formal assessment can be accomplished using Humphrey or Goldmann visual fields.

\section{Eyelid vital signs}

In regard to the assessment of ptosis, careful measurements of eyelid function should be gathered as a means to differentiate many underlying pathologies. The normal position of the upper lid margin is about 0.5-2.0 $\mathrm{mm}$ below the superior corneal limbus. The average adult vertical palpebral fissure (distance between the upper and lower eyelid margin) measures between 8 and $11 \mathrm{~mm}^{[5]}$. The vertical palpebral fissure can be further subdivided into margin-reflex-distance 1 (MRD1) and margin-reflex-distance 2 (MRD2). MRD1 is the vertical distance from upper eyelid margin to the corneal light reflex with the average MRD1 being 4-5 mm. In cases of severe ptosis, MRD1 can be zero or have a negative value ${ }^{[78]}$. $\mathrm{MRD} 2$ is the vertical distance from the lower eyelid margin to the corneal light reflex and can be used to determine inferior scleral show. As a general rule, the lower lid margin should rest at the level of the inferior limbus. Levator function is assessed by first neutralizing the action of the frontalis muscle via digital pressure and subsequently measuring full excursion of the upper eyelid from downgaze to upgaze. This should be 10-15 $\mathrm{mm}$ in normal patients, 8-10 $\mathrm{mm}$ with good levator function, 5-7 $\mathrm{mm}$ with fair levator function, and 1-4 mm with poor levator function ${ }^{[3]}$. Upper eyelid crease position is measured as the distance between the margin of the upper eyelid and the eyelid crease. The eyelid crease tends to be slightly higher in females $(10-11 \mathrm{~mm})$ than males $(8-9 \mathrm{~mm})$. It is worth noting that the upper eyelid crease in Asian eyelids is typically lower or absent with or without ptosis. In the appropriate clinical context, deviations from these average values can confirm the presence of ptosis, and levator function should be used to further classify the mechanism ${ }^{[79]}$. Lagophthalmos should also be measured when present, as this pathologic gap between closed eyelids can play an important role in surgical planning and preoperative counseling.

\section{Ancillary testing}

A tailored workup should be initiated if the underlying etiology of a patient's ptosis remains unclear. A basic laboratory evaluation can include a comprehensive metabolic panel, complete blood count, erythrocyte sedimentation rate, and C-reactive protein. Thyroid function tests (TSH, T3, T4), thyroid antibody panel, and CT/MRI orbits without contrast can be ordered if thyroid eye disease is suspected. If clinical suspicion for ocular MG is high, a CT chest (thymoma) and single fiber EMG (88\%-99\% sensitivity) may be necessary, as acetylcholine receptor antibodies are present in only $50 \%$ of ocular MG patients ${ }^{[80]}$. Genetic testing, electromyography, and a muscle biopsy may be warranted when a primary inherited myopathy is suspected (CPEO, KSS, MELAS, OPMD, MD). If concern for KSS is present, an EKG and cardiology referral should be placed to evaluate for heart block. Genetic testing can also be considered in isolated congenital ptosis, BPES, CFEOM, DRS, and congenital myasthenic syndrome ${ }^{[81]}$. The results for BPES can serve as a useful adjunct in patient counseling as type I BPES is linked to female infertility. Neuroimaging is likely warranted if the clinical examination shows signs of an orbital mass, abnormal pupillary findings, cranial neuropathies, or systemic neurologic symptoms. A suspected orbital or intracranial mass should receive an orbital or brain MRI with fat suppression and gadolinium contrast. The presence of HS should warrant MRI evaluation of the brain, spine, and thorax. When there is concern for an aneurysm causing a CN-III palsy, CTA or MRA can be ordered. While CTA/MRA has excellent detection rates, the gold standard of cerebral angiography can be pursued when initial imaging findings are inconclusive $e^{[17,40,41]}$. 


\section{TREATMENT}

Ptosis must first be properly evaluated and diagnosed before suitable treatment options can be discussed. Certain causes of ptosis can be observed for spontaneous resolution after correction of the underlying condition, while others will require individualized treatment to address functional or cosmetic concerns. Intervention can include pharmacological and/or surgical therapy.

\section{Observation}

Mild ptosis of traumatic or neurogenic origin can often improve spontaneously. In regard to traumatic ptosis, an observational period of 3 months or more is allowed for spontaneous recovery from traumatic edema and hemorrhage. Subsequent mild ptosis with good levator function and MRD1 can be further observed with little functional deficit ${ }^{[66]}$. When evaluating neurogenic ptosis resulting from a microvascular ischemic CN-III palsy, $70 \%$ of patients showed an improvement over a 3-month observational period ${ }^{[2]}$. Likewise, the majority of supranuclear neurogenic ptosis that occurred secondary to cerebrovascular accident improved within 2-3 days of onset ${ }^{[49]}$. Specific types of ptosis may benefit from observation with the aid of certain prosthetic devices ${ }^{[82,83]}$. Glasses can be made inexpensively with wire attachments known as "crutches" that can be positioned to elevate the upper eyelid and delay surgery in poor surgical candidates ${ }^{[84]}$. Observation is also appropriate in congenital ptosis without amblyogenic risk or aponeurotic ptosis, where the patient is not bothered, and no further systemic workup or treatment is warranted.

\section{Pharmacologic}

Medical therapy can be utilized to treat certain forms of ptosis or it can be used to preoperatively maximize the chance of successful blepharoptosis repair. Thyroid eye disease can uncommonly present with ptosis and must be managed with corticosteroids and/or immunomodulatory therapy to ensure 6-9 months of stability before eyelid surgery can be considered ${ }^{[85,86]}$. Given the significant fluctuation of levator function in MG, cholinesterase inhibitors and/or corticosteroids should ideally be titrated to ensure stabilization for 3-4 years prior to surgical correction ${ }^{[43]}$. While not true ptosis, neuromyotonia of the levator palpebrae superioris has been documented to cause pseudoptosis of the contralateral eye via Hering's law of equal innervation. This responds well to carbamazepine, which can also improve associated diplopia from neuromyotonia of the extraocular muscles ${ }^{[87]}$. Botulinum toxin injection into the pretarsal orbicularis oculi can be successfully employed to manage mild acquired aponeurotic ptosis or acquired neurogenic pseudoptosis secondary to aberrant regeneration of $\mathrm{CN}-\mathrm{VII}{ }^{[88,89]}$. Likewise, true ptosis that can be induced as a side effect of botulinum toxin can be reversed with the use of apraclonidine drops or pyridostigmine $^{[48,90]}$.

\section{Surgery}

Definitive therapy in most cases of ptosis is surgical intervention. This is often necessitated by the presence of amblyopia or the inability to perform activities of daily living such as reading or driving. There are various methods of ptosis repair and can broadly be classified into external and internal approaches ${ }^{[91]}$. The etiology of the ptosis and severity of levator dysfunction will often determine the most appropriate approach. Additionally, the surgeon's preference and experience can also decide the method selected. Regardless of the technique, ptosis repair can be performed in the office setting with local infiltration or in the operating suite typically under sedation.

\section{Surgical management}

Internal approach (transconjunctival)

The internal surgical approach elevates ptotic eyelids by removing conjunctiva, Müller's muscle, and/ or portions of the tarsal plate to correct mild ptosis with intact levator function. This remains a popular approach as of 2011 with $74 \%$ of respondent ASOPRS members performing a variation of an internal approach to ptosis correction ${ }^{[92]}$. There are multiple adaptations, including the Müller's muscle-conjunctiva resection and the Fasanella-Servat procedure. 
The Fasanella-Servat procedure was initially described in 1961 as a modification of Blascovic's levator resection, which has been applied to many forms of ptosis including congenital, myogenic, neurogenic (Horner syndrome), and traumatic. The Fasanella-Servat procedure addresses ptosis up to $3 \mathrm{~mm}$ with intact levator function ( $>10 \mathrm{~mm}$ ) by resecting $3 \mathrm{~mm}$ of Müller's muscle, $3 \mathrm{~mm}$ of the superior tarsal plate, and $6 \mathrm{~mm}$ of conjunctiva ${ }^{[93]}$. The original procedure has been modified in both the suturing technique as well the amount and type of tissue resected ${ }^{[94-99]}$. A graded shortening guideline has been recommended with $1 \mathrm{~mm}$ of eyelid lift for every $2 \mathrm{~mm}$ of tarsectomy or $2 \mathrm{~mm}$ of conjunctiva-Müller's muscle resection performed. Successful symmetric eyelid station within $1.5 \mathrm{~mm}$ was achieved in $96 \%$ of study patients using this guideline ${ }^{[100]}$. While there are cosmetic benefits of avoiding a visible scar, tarsal instability and ocular surface complications have been significant drawbacks. Eyelid peaking, lagophthalmos, and contour asymmetry can result from aggressive tarsectomy and a secondary acquired ptosis can even result from inadequate tarsectomy. Appropriate initial tarsectomy can in some cases preclude the use of a tarsal graft during eyelid reconstruction from trauma or malignancy. Ocular surface disease can occur postoperatively in the short term via wound irregularity causing cornea abrasions and the long term via keratitis sicca as a result of tarsal meibomian gland resection ${ }^{[91,100,101]}$. While the Fasanella-Servat procedure remains a versatile approach for correcting mild ptosis, it has lost popularity in favor of more conventional methodologies.

Müller's muscle-conjunctiva resection (MMCR) requires excellent levator function (>10 $\mathrm{mm}$ ) and is ideal for mild ptosis of $1-2 \mathrm{~mm}^{[102]}$. The traditional approach requires preoperative phenylephrine testing (alpha-1 adrenergic agonist) to ensure candidacy by establishing viable Müller's muscle excursion. Three drops of $2.5 \%$ phenylephrine are given over the course of 1 minute and a final drop is given 1 minute later. Lid elevation of 1-2 mm after several minutes is considered a successful response that establishes eligibility for $\mathrm{MMCR}^{[91,103]}$. However, there have been challenges to this fitness test with success being reported in "phenylephrine-negative" patients as well as HS patients with Müller's muscle denervation ${ }^{[104,105]}$. Ben Simon et al. ${ }^{[42]}$ found that phenylephrine testing on average underestimated postoperative correction by $40 \%$. Histopathological analysis of Fasanella-Servat su rgical specimens support these findings where $87.5 \%$ of samples taken by Buckman et al ${ }^{[106]}$ found minimal amounts of smooth muscle. This has subsequently led to theories that the mechanism of internal approaches such as MMCR may be independent of Müller's muscle function and are rather a reflection of posterior lamellar shortening ${ }^{[42,101,106]}$. The original recommendation by Putterman and Fett ${ }^{[107]}$ was $8.25 \mathrm{~mm}$ of resection with a range of 6.5-9.5 mm based on the contralateral eyelid response to phenylephrine. A 4:1 rule has subsequently been proposed, where $4 \mathrm{~mm}$ of resection is performed for every $1 \mathrm{~mm}$ of desired lid elevation ${ }^{[108-110]}$. MMCR remains a popular choice for mild ptosis. Putterman and Fett ${ }^{[107]}$ found that $90 \%$ of acquired ptosis patients and $100 \%$ of congenital ptosis patients had successful outcomes within $1.5 \mathrm{~mm}$ of the contralateral eyelid. Only $0.8 \%$ (2/232) required reoperation. Alteration of the natural eyelid crease is minimal by virtue of the anatomical approach, no intraoperative patient cooperation is required, and there is relatively rapid recovery with less postoperative edema and ecchymosis ${ }^{[91]}$. MMCR can be more aesthetically appealing for patients, as it avoids a visible scar on the eyelid, but if blepharoplasty is also desired, an additional anterior incision must be made. MMCR is classically avoided in patients with glaucoma filtering blebs and corneal pathology because of the risk of potential conjunctival scarring. However, case reports have refuted this conventional wisdom with successful outcomes ${ }^{[111-113]}$. The main drawback limiting the expansion of MMCR is the inability to address ptosis $>2 \mathrm{~mm}$, which must be addressed by external surgical approach.

\section{External approach (transcutaneous)}

The external surgical approach elevates ptotic eyelids by addressing the levator palpebrae superioris or frontalis muscle. Ptosis ranging from mild to severe can be addressed via levator advancement/resection or frontalis sling depending on the degree of levator dysfunction.

External levator advancement was first popularized by Jones et al. ${ }^{[114]}$ in his 1975 publication, The Cure of Ptosis by Aponeurotic Repair. It can address a wide range of ptosis etiologies with levator function 

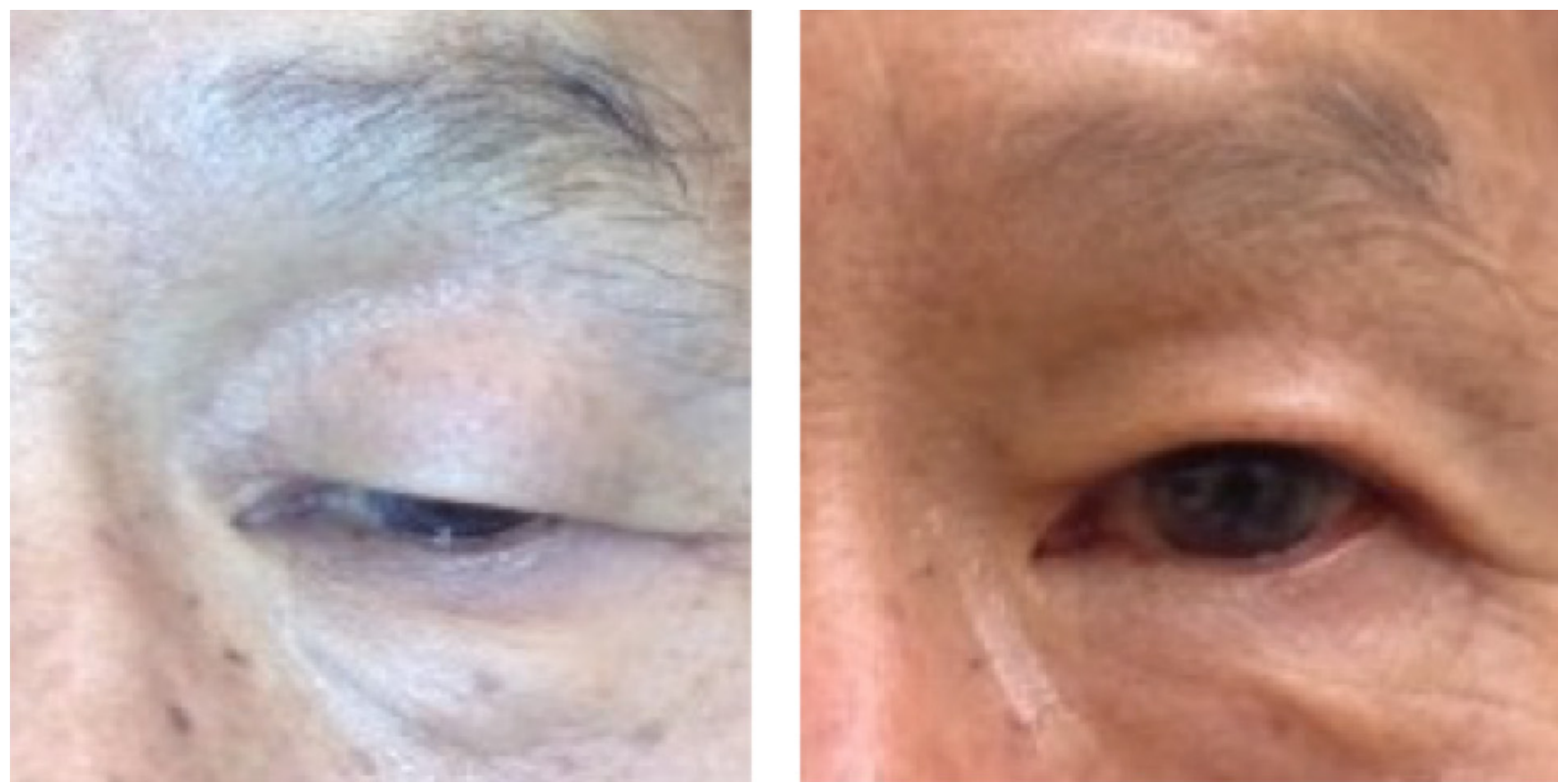

Figure 1. External photograph of an older man with upper eyelid acquired aponeurotic ptosis and preserved levator function, shown before and after levator advancement

greater than $4 \mathrm{~mm}$ [Figure 1]. Involutional dehiscence of the levator aponeurosis forms the ideological basis as levator advancement seeks to directly reverse this process by re-attaching the levator aponeurosis to the anterior surface of superior tarsal border ${ }^{[115,116]}$. This results in elevation of the eyelid margin and restoration of the eyelid crease to a lower, more youthful position. The traditional approach with a 20- to $22-\mathrm{mm}$ lid crease skin incision affords the convenience of a same-incision blepharoplasty. However, there are also progressive modifications towards small incision techniques that allow for improved cosmesis in the absence of blepharoplasty. Lucarelli and Lemke ${ }^{[117]}$ first described an $8-\mathrm{mm}$ lid crease skin incision in 1999 that was modified to have minimal internal dissection by Frueh et al. ${ }^{[118]}$ in 2004 . This minimalist technique was found to have equivalent ptosis correction with a more desirable contour and shorter operative time. Although success rates of traditional levator advancement vary between $70 \%$ and $95 \%$ using conscious sedation, there are certain caveats ${ }^{[115,119-122]}$. Overcorrection can occur as a result of falsely lowered intraoperative eyelid height seen in excessive sedation, increased eyelid bulk (excessive local anesthesia, hematoma, edema), and excessively bright operative lights (patient squinting). Undercorrection can also occur as a result of falsely elevated intraoperative eyelid height seen in epinephrine activation of Müller's muscle and local anesthetic effect on orbicularis oculi ${ }^{[123,124]}$. Ultimately $8 \%-14 \%$ of patients require revision with an estimated $96 \%$ achieving satisfactory results after early office based revision ${ }^{[120,125-127]}$. McCord et al. ${ }^{[128]}$ developed a three-step technique that does not rely on voluntary patient cooperation to address adults that require general anesthesia secondary to poor cooperation or simultaneous procedures. This achieved contralateral eyelid asymmetry of less than $1 \mathrm{~mm}$ in $85 \%$ of patients and only recorded a reoperation rate of $2.5 \%{ }^{[128]}$. Thus, with such versatility and favorable outcomes, levator aponeurosis advancement has become one of the most commonly performed ptosis correction procedures in modern oculoplastic practices.

Levator palpebrae superioris resection is a commonly used approach for congenital ptosis with levator function greater than $4 \mathrm{~mm}$ [Figure 2] $]^{[129,130]}$. The amount of resection is generally based on a combination of Berke and Beard surgical scaling charts ${ }^{[131,132]}$. Beard guidelines rely upon preoperative levator function and degree of ptosis to determine an amount of levator resection, while Berke recommendations use levator function to determine intraoperative lid height regardless of the amount of levator resection. Although 

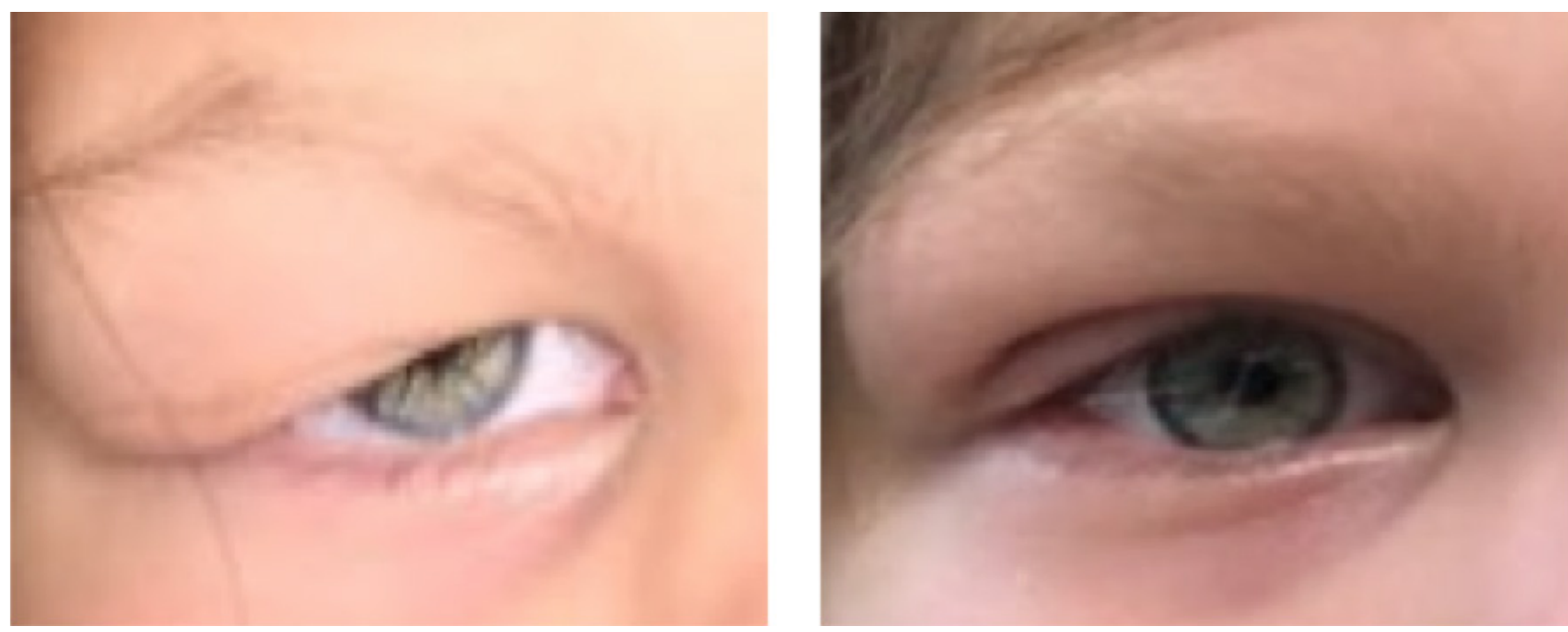

Figure 2. External photograph of a young child with right-sided congenital myogenic ptosis and moderate levator function, shown before and after levator resection

both are considered to be useful guidelines, accurate prediction of surgical outcomes remains elusive. Undercorrection with severe levator dysfunction and overcorrection with mild levator dysfunction remain the most commonly reported complications ${ }^{[133]}$. Rates of successful outcomes range between $69 \%$ and $88 \%$ on the basis of surgeon interpretation of combined Berke and Beard guidelines ${ }^{[15,133-135]}$. Thus, modifications addressing preoperative assessment and surgical technique have been suggested. In addition to individual surgeon modifications, formal guidelines have been compiled by Finsterer ${ }^{[3]}$ and simplified by Carraway and Vincent ${ }^{[136]}$ to a general rule of $4 \mathrm{~mm}$ of levator resection for every $1 \mathrm{~mm}$ of ptosis present. Given the difficulty with predicting outcomes preoperatively, an intraoperative adjustable suture method employed under conscious sedation found that $90 \%$ of congenital ptosis patients were able to achieve satisfactory outcomes. However, this method requires intraoperative patient cooperation which is not always present in the pediatric population ${ }^{[137]}$. A small incisional approach (10- to $12-\mathrm{mm}$ incision) has also been suggested with equivalent successful outcomes in $74 \%$ of patients, defined as less than $1 \mathrm{~mm}$ of asymmetry between the contralateral eyelid ${ }^{[138]}$. Despite the increasing success through serial modifications, there remains a limited role in adults as it often results in lagophthalmos. Children, without pre-existing ocular surface issues, tolerate large degrees of lagophthalmos well, while adults will often develop exposure keratopathy.

Frontalis suspension is a great option for severe ptosis with levator function of $4 \mathrm{~mm}$ or less [Figure 3]. It has been successfully employed in many etiologies of myogenic and neurogenic ptosis, including isolated congenital myogenic ptosis, BPES, OPMD, CPEO, Marcus Gunn jaw-winking, and CN-III palsies $^{[34,134,139-142]}$. The frontalis muscle is bridged to the superior tarsal plate and epitarsal tissue to allow for improved eyelid position in primary gaze. With contraction of the frontalis muscle, the upper eyelid can be elevated and thus bypasses the poorly functioning levator. The bridging material can be autogenous, allogeneic, or alloplastic. Autogenous tensor fascia lata is considered to be the gold standard suspension material as it has low rates of infection, extrusion, and recurrence, coupled with elastic properties that allow for adequate eyelid closure ${ }^{[143-145]}$. Functional success rates in the pediatric population range from $73 \%$ to $94 \%$ when seeking to clear the visual axis; however, cosmetic outcomes were less desirable, with $85 \%$ achieving satisfactory lid contour, $65 \%$ achieving satisfactory symmetry, and $67 \%$ achieving a satisfactory lid crease ${ }^{[144,146,147]}$. Autogenous palmaris longus tendon and temporalis fascia grafts have also shown comparable results in smaller study group ${ }^{[148-150]}$. Despite promising functional outcomes, there can be certain limitations when choosing autogenous tensor fascia lata. Donor site morbidity, donor site scarring, and graft contracture/fibrosis can lead to suboptimal outcomes ${ }^{[151]}$. The patient must also be at least 3 years old with a minimum height of 38 inches to successfully harvest the graft. Although ptosis surgery 

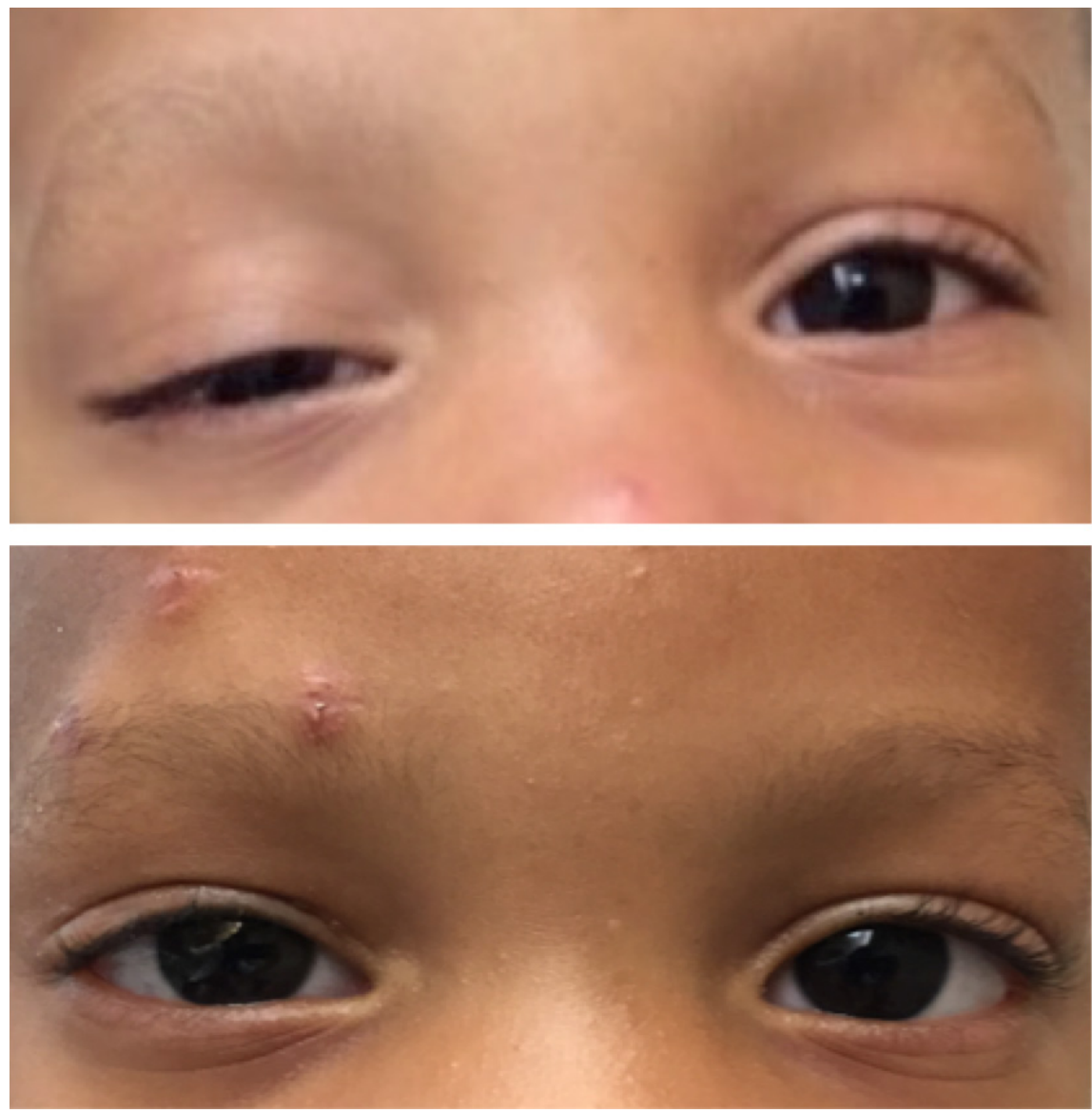

Figure 3. External photograph of a young child with right-sided congenital myogenic ptosis and poor levator function, shown before and after a frontalis suspension with autogenous tensor fascia lata

is commonly delayed until the age of 3 to allow for maturation of anatomical structures, amblyogenic risk often necessitates urgent intervention at an earlier age ${ }^{[67,152]}$. Allogeneic banked fascia lata is a frontalis suspension material that can be considered in children under the age of 3 with significant amblyogenic risk. Initial postoperative success is common; however, significant ptosis recurrence rates ranging from $28 \%$ to $51 \%$ have been observed ${ }^{[144,153,154]}$. Postoperative side effects also include a robust initial inflammatory response and the potential risk of infectious disease transmission to the patient. To minimize infectious risk, the donor tissue is often irradiated and coupled with host serologic testing to exclude a wide array of transmissible diseases. The imperfections that exist in banked fascia have driven investigations into alloplastic frontalis suspension materials as an alternative for both adults and children under the age of 3. Silicone rods have emerged as the most commonly employed synthetic material secondary to ease of placement and adjustability to minimize or eliminate lagophthalmos ${ }^{[155]}$. Mersilene mesh, porous polytetrafluoroethylene (GoreTex), and monofilament/polyfilament nylon are additional synthetic options with varying rates of recurrence and other complications. Compared to allogeneic banked fascia, there are higher rates of infection, wound granuloma, and extrusion [Figure 4]. However, synthetic materials tend to have less incorporation into surrounding tissue than allogeneic fascia, allowing for easier adjustment or removal during subsequent procedures ${ }^{[144]}$. Independent of the frontalis suspension material used, frontalis suspension procedures have significant risks of lagophthalmos, lid lag in downgaze, loss of eyelid crease, poor apposition to the globe, geometric tenting of the pretarsal skin, and residual amblyopia. Thus, patient selection must consider the presence of reduced corneal sensation, poor tear production, and poor Bell's phenomenon to prevent disappointing postoperative outcomes ${ }^{[81]}$. 


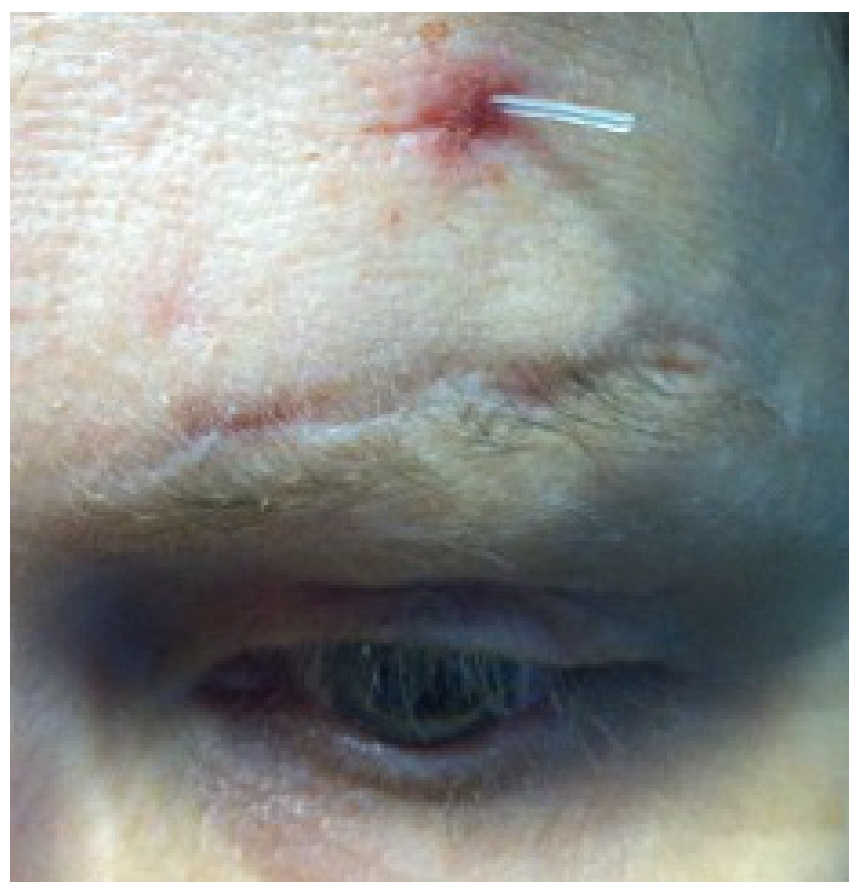

Figure 4. External photograph of an older woman with left-sided acquired neurogenic ptosis and poor levator function repaired via frontalis suspension with a silicone rod. Extrusion of the silicone rod occurred postoperatively

When the appropriate procedure is selected, both external and internal approaches are highly successful in elevating the upper eyelid. Swelling, bruising, and varying degrees of discomfort are to be expected during the immediate postoperative period. Overcorrection, undercorrection, asymmetry, and contour issues remain common complications for all procedures, and revisions are commonly needed to achieve successful outcomes. While ptosis repair remains one of the most common procedures performed, it still remains one of the most challenging surgeries ${ }^{[91]}$.

\section{CONCLUSION}

Ptosis can represent a myriad of local and systemic conditions. The pathogenesis of ptosis can be uncovered with a detailed understanding of the neuromuscular pathway that retracts and protracts the eyelid. To triage life-threatening, vision-threatening, or aesthetically unappealing ptosis, one must be able to effectively examine and interview patients. Determining whether the ptosis is aponeurotic, myogenic, neurogenic, mechanical, or traumatic can enable the practitioner to successfully counsel and advise treatment options including surgical intervention. Ultimately the appropriate level of empathy and close patient-physician relationships are necessary in ensuring patient satisfaction, given the often-challenging nature of repairing eyelid ptosis.

\section{DECLARATIONS}

\section{Authors' contributions}

Substantial contributions to structure of the review, review of the literature, and editing the manuscript: Kim HJ

Performed review of literature and drafted the manuscript: Floyd MT

\section{Availability of data and materials}

Not applicable. 


\section{Financial support and sponsorship}

None.

\section{Conflicts of interest}

Both authors declared that there are no conflicts of interest.

\section{Ethical approval and consent to participate}

Not applicable.

\section{Consent for publication}

Written informed consent has been obtained for all subjects whose photos were used in this manuscript.

\section{Copyright}

(C) The Author(s) 2021

\section{REFERENCES}

1. Ptosis. Available from: https://www.merriam-webster.com/dictionary/ptosis. [Last accessed on 27 Nov 2020]

2. Belphar-. Available from: https://www.merriam-webster.com/dictionary/blephar-. [Last accessed on 27 Nov 2020]

3. Finsterer J. Ptosis: causes, presentation, and management. Aesthetic Plast Surg 2003;27:193-204.

4. Frueh BR. The mechanistic classification of ptosis. Ophthalmology 1980;87:1019-21.

5. Sand JP, Zhu BZ, Desai SC. Surgical anatomy of the eyelids. Facial Plast Surg Clin North Am 2016;24:89-95.

6. Lin LK. Eyelid anatomy and function. In: Holland EJ, Mannis MJ, Lee WB, editors. Ocular surface disease: cornea, conjunctiva and tear film. Elsevier Inc; 2013. pp. 11-5.

7. Dutton JJ. Atlas of clinical and surgical orbital anatomy. 2nd ed. Elsevier Inc; 2011; pp. 51-82.

8. Lim JM, Hou JH, Singa RM, Aakalu VK, Setabutr P. Relative incidence of blepharoptosis subtypes in an oculoplastics practice at a tertiary care center. Orbit 2013;32:231-4.

9. Martin Jr JJ, Tenzel RR. Acquired ptosis: dehiscences and disinsertions. Are they real or iatrogenic? Ophthalmic Plast Reconstr Surg 1992;8:130-2; discussion 133.

10. Godfrey KJ, Korn BS, Kikkawa DO. Blepharoptosis following ocular surgery: identifying risk factors. Curr Opin Ophthalmol 2016;27:31-7.

11. Kersten RC, de Conciliis C, Kulwin DR. Acquired ptosis in the young and middle-aged adult population. Ophthalmology 1995;102:924-8.

12. Koursh DM, Modjtahedi SP, Selva D, Leibovitch I. The blepharochalasis syndrome. Surv Ophthalmol 2009;54:235-44.

13. Bleyen I, Hiemstra CA, Devogelaere T, van den Bosch WA, Wubbels RJ, Paridaens DA. Not only hard contact lens wear but also soft contact lens wear may be associated with blepharoptosis. Can J Ophthalmol 2011;46:333-6.

14. Martin PA, Rogers PA. Congenital aponeurotic ptosis. Aust N Z J Ophthalmol 1988;16:291-4.

15. Berry-Brincat A, Willshaw H. Paediatric blepharoptosis: a 10-year review. Eye (Lond) 2009;23:1554-9.

16. Griepentrog GJ, Diehl NN, Mohney BG. Incidence and demographics of childhood ptosis. Ophthalmology 2011;118:1180-3.

17. Díaz-Manera J, Luna S, Roig C. Ocular ptosis: differential diagnosis and treatment. Curr Opin Neurol 2018;31:618-27.

18. Baldwin HC, Manners RM. Congenital blepharoptosis: a literature review of the histology of levator palpebrae superioris muscle. Ophthalmic Plast Reconstr Surg 2002;18:301-7.

19. Nalci Baytaroğlu H, Kaya B, Korkusuz P, Hoşal MB. A study of histopathologic evaluation and clinical correlation for isolated congenital myogenic ptosis and aponeurotic ptosis. Ophthalmic Plast Reconstr Surg 2020;36:380-4.

20. Salman MS, Clark IH. Eyelid retraction in isolated unilateral congenital blepharoptosis. Front Neurol 2017;8:190.

21. Surve A, Sharma MC, Pushker N, Bajaj MS, Meel R, Kashyap S. A study of changes in levator muscle in congenital ptosis. Int Ophthalmol 2019;39:1231-8.

22. Strømme P, Sandboe F. Blepharophimosis-ptosis-epicanthus inversus syndrome (BPES). Acta Ophthalmol Scand 1996;74:45-7.

23. Wong VA, Beckingsale PS, Oley CA, Sullivan TJ. Management of myogenic ptosis1 1The authors have no proprietary interest in any products related to this manuscript. Ophthalmology 2002;109:1023-31.

24. Yu Wai Man CY, Smith T, Chinnery PF, Turnbull DM, Griffiths PG. Assessment of visual function in chronic progressive external ophthalmoplegia. Eye (Lond) 2006;20:564-8.

25. Anders JM. An interesting case of chronic lead poisoning with relapse following fresh exposure. JAMA 1914;LXII:1164-5.

26. Song A, Carter KD, Nerad JA, Boldt C, Folk J. Steroid-induced ptosis: case studies and histopathologic analysis. Eye (Lond) 2008;22:491-5.

27. Pfeffer G, Côté HC, Montaner JS, Li CC, Jitratkosol M, Mezei MM. Ophthalmoplegia and ptosis: mitochondrial toxicity in patients receiving HIV therapy. Neurology 2009;73:71-2.

28. Rasiah S, Hardy TG, Elder JE, Ng CY, Lenake M, McNab AA. Aetiology of acquired blepharoptosis in young adults. Orbit 2018;37:59-64. 
29. Kung NH, Van Stavern GP. Isolated ocular motor nerve palsies. Semin Neurol 2015;35:539-48.

30. Alonso P, Bescansa E, Salas J, de Haro J, Redondo A, Rioja L. Perineural spread of cutaneous squamous cell carcinoma manifesting as ptosis and ophthalmoplegia (Orbital Apex Syndrome). Br J Plast Surg 1995;48:564-8.

31. Sanders S, Kawasaki A, Purvin VA. Patterns of extraocular muscle weakness in vasculopathic pupil-sparing, incomplete third nerve palsy. J Neuroophthalmol 2001;21:256-9.

32. Dhume KU, Paul KE. Incidence of pupillary involvement, course of anisocoria and ophthalmoplegia in diabetic oculomotor nerve palsy. Indian J Ophthalmol 2013;61:13-7.

33. Trobe JD. Third nerve palsy and the pupil. Footnotes to the rule. Arch Ophthalmol 1988;106:601-2.

34. Bagheri A, Borhani M, Salehirad S, Yazdani S, Tavakoli M. Blepharoptosis associated with third cranial nerve palsy. Ophthalmic Plast Reconstr Surg 2015;31:357-60.

35. Schumacher-feero LA, Yoo K, Mendiola Solari F, Biglan AW. Third cranial nerve palsy in children. Am J Ophthalmol 1999;128:216-21.

36. Hamed LM. Associated neurologic and ophthalmologic findings in congenital oculomotor nerve palsy. Ophthalmology 1991;98:708-14.

37. Assaf AA. Congenital innervation dysgenesis syndrome (CID)/congenital cranial dysinnervation disorders (CCDDs). Eye (Lond) 2011;25:1251-61.

38. Traboulsi EI. Congenital cranial dysinnervation disorders and more. J AAPOS 2007;11:215-7.

39. Walton KA, Buono LM. Horner syndrome. Curr Opin Ophthalmol 2003;14:357-63.

40. Martin TJ. Horner syndrome: a clinical review. ACS Chem Neurosci 2018;9:177-86.

41. Barrea C, Vigouroux T, Karam J, Milet A, Vaessen S, Misson JP. Horner syndrome in children: a clinical condition with serious underlying disease. Neuropediatrics 2016;47:268-72.

42. Ben Simon GJ, Lee S, Schwarcz RM, McCann JD, Goldberg RA. Muller's muscle-conjunctival resection for correction of upper eyelid ptosis: relationship between phenylephrine testing and the amount of tissue resected with final eyelid position. Arch Facial Plast Surg 2007;9:413-7.

43. Shimizu Y, Suzuki S, Nagasao T, et al. Surgical treatment for medically refractory myasthenic blepharoptosis. Clin Ophthalmol 2014;8:1859-67.

44. Brogan K, Farrugia ME, Crofts K. Ptosis surgery in patients with myasthenia gravis: a useful adjunct to medical therapy. Semin Ophthalmol 2018;33:429-34.

45. Bradley EA, Bartley GB, Chapman KL, Waller RR. Surgical correction of blepharoptosis in patients with myasthenia gravis. Ophthalmic Plast Reconstr Surg 2001;17:103-10.

46. Pavone P, Cho SY, Praticò AD, Falsaperla R, Ruggieri M, Jin DK. Ptosis in childhood: a clinical sign of several disorders: case series reports and literature review. Medicine (Baltimore) 2018;97:e12124.

47. Klein AW. Contraindications and complications with the use of botulinum toxin. Clin Dermatol 2004;22:66-75.

48. Karami M, Taheri A, Mansoori P. Treatment of botulinum toxin-induced eyelid ptosis with anticholinesterases. Dermatol Surg 2007;33:1392-4; discussion 1394-5.

49. Averbuch-Heller L, Leigh RJ, Mermelstein V, Zagalsky L, Streifler JY. Ptosis in patients with hemispheric strokes. Neurology 2002;58:620-4.

50. Kazmi SS, Nejat F, Khotaei GT, Ghaheri H. Ptosis as a presenting feature of bacterial meningitis. Pediatr Infect Dis J 2006;25:570.

51. Li G, Zhang Y, Zhu X, Hou K. Transient traumatic isolated neurogenic ptosis after a mild head trauma: a case report. BMC Ophthalmol 2015;15:161.

52. Gascón-Bayarri J, Campdelacreu J, García-Carreira MC, et al. Wernicke's encephalopathy in non-alcoholic patients: a series of 8 cases. Neurologia 2011;26:540-7.

53. Gonçalves AC, Moura FC, Monteiro ML. Bilateral progressive enophthalmos as the presenting sign of metastatic breast carcinoma. Ophthalmic Plast Reconstr Surg 2005;21:311-3.

54. Ho ST, Valenzuela AA. A deadly droop: small cell lung cancer presenting as upper eyelid ptosis. Vis Pan-Am 2014;13:56-8.

55. Bianciotto C, Demirci H, Shields CL, Eagle RC Jr, Shields JA. Metastatic tumors to the eyelid: report of 20 cases and review of the literature. Arch Ophthalmol 2009;127:999-1005.

56. Greco F, Sabatino L, Sabatino F, Casale M, Quattrocchi CC, Zobel BB. Unilateral blepharoptosis from renal cell carcinoma. J Kidney Cancer VHL 2016;3:11-5.

57. Hsu M, Chung C, Chang C, Hu P, Hsu S. Ptosis as an initial manifestation of orbital lymphoma: a case report. Kaohsiung J Med Sci 2006;22:194-8.

58. Chaudhry IA, Shamsi FA, Elzaridi E, et al. Outcome of treated orbital cellulitis in a tertiary eye care center in the middle East. Ophthalmology 2007;114:345-54.

59. Avery RA, Dombi E, Hutcheson KA, et al. Visual outcomes in children with neurofibromatosis type 1 and orbitotemporal plexiform neurofibromas. Am J Ophthalmol 2013;155:1089-94.e1.

60. Avery RA, Katowitz JA, Fisher MJ, et al; OPPN Working Group. Orbital/periorbital plexiform neurofibromas in children with neurofibromatosis type 1: multidisciplinary recommendations for care. Ophthalmology 2017;124:123-32.

61. Jurdy L, Merks JH, Pieters BR, et al. Orbital rhabdomyosarcomas: a review. Saudi J Ophthalmol 2013;27:167-75.

62. Tatli B, Saribeyoğlu ET, Aydinli N, Calişkan M, Anak S. Neuroblastoma: an unusual presentation with bilateral ptosis. Pediatr Neurol 2004;30:284-6.

63. Al Rasheed R, AlSamnan M. Congenital giant orbital eccrine hidrocystoma. Am J Ophthalmol Case Rep 2019;16:100570.

64. Hoang A, Maugans T, Ngo T, Ikeda J. Nontraumatic orbital roof encephalocele. J AAPOS 2017;21:81-3. 
65. Pellant A, Chrobok V, Mejzlík J. Anterior orbital meningoencephalocele. Eur Arch Otorhinolaryngol 2010;267:1475-6.

66. Jacobs SM, Tyring AJ, Amadi AJ. Traumatic ptosis: evaluation of etiology, management and prognosis. $J$ Ophthalmic Vis Res 2018;13:447-52.

67. Patel K, Carballo S, Thompson L. Ptosis. Dis Mon 2017;63:74-9.

68. Peer Mohamed BA, Patil SG. Psychogenic unilateral pseudoptosis. Pediatr Neurol 2009;41:364-6.

69. Biousse V, Newman NJ. Neuro-ophthalmology illustrated. 2nd ed. New York: Thieme Medical Publishers; 2016.

70. Chen C, Malhotra R, Muecke J, Davis G, Selva D. Aberrant facial nerve regeneration (AFR): an under-recognized cause of ptosis. Eye (Lond) 2004;18:159-62.

71. Gold DR, Shin RK, Bhatt NP, Eggenberger ER. Aberrant regeneration of the third nerve (oculomotor synkinesis). Pract Neurol 2012;12:390-1.

72. Sibony PA, Lessell S, Gittinger JW. Acquired oculomotor synkinesis. Surv Ophthalmol 1984;28:382-90.

73. WALSH FB. Third nerve regeneration; a clinical evaluation. Br J Ophthalmol 1957;41:577-98.

74. Schumacher-Feero LA, Yoo KW, Solari FM, Biglan AW. Results following treatment of third cranial nerve palsy in children. Trans Am Ophthalmol Soc 1998;96:455-72; discussion 472-4.

75. Bahceci Simsek I. Association of upper eyelid ptosis repair and blepharoplasty with headache-related quality of life. JAMA Facial Plast Surg 2017;19:293-7.

76. Jindal K, Sarcia M, Codner MA. Functional considerations in aesthetic eyelid surgery. Plast Reconstr Surg 2014;134:1154-70.

77. Bullock JD, Warwar RE, Bienenfeld DG, Marcinisszyn SL, Markert RJ. Psychosocial implications of blepharoptosis and dermatochalasis. Trans Am Ophthalmol Soc 2001;99:65-71; discussion 71-2.

78. America academy of ophthalmology. Palmetto GBA LCD Policies. Available from: https://www.aao.org/practice-management/coding/ lcd-policies/palmetto. [Last accessed on 27 Nov 2020]

79. Neimkin MG, Holds JB. Evaluation of eyelid function and aesthetics. Facial Plast Surg Clin North Am 2016;24:97-106.

80. Noel MECB, Burkat CN, Jirawuthiworavong GV, et al. Myasthenia gravis. Available from: https://eyewiki.aao.org/Myasthenia_Gravis. [Last accessed on 27 Nov 2020]

81. SooHoo JR, Davies BW, Allard FD, Durairaj VD. Congenital ptosis. Surv Ophthalmol 2014;59:483-92.

82. Oya Y, Yoshida H, Takeshima M, et al. Beneficial effect of eyelid make-up (natural rubber latex) to induce a new fold in the treatment of blepharoptosis in myotonic dystrophy. Rinsho Shinkeigaku 2000;40:483-6.

83. Osaki TH, Osaki MH, Belfort R Jr, Osaki T, Sant'anna AE, Haraguchi DK. Management of progressive myopathic blepharoptosis with daily application of octyl-2-cyanoacrylate liquid bandage. Ophthalmic Plast Reconstr Surg 2009;25:264-6.

84. Takagi S, Hosokawa K, Yano K, Kunihiro N, Tateki K. Crutch glasses for blepharoptosis. Plast Reconstr Surg 2002;109:2605.

85. Scruggs RT, Black EH. Thyroid eye disease with significant levator involvement and ptosis: a case report. Ophthalmic Plast Reconstr Surg 2015;31:e153-4.

86. Boulos PR, Hardy I. Thyroid-associated orbitopathy: a clinicopathologic and therapeutic review. Curr Opin Ophthalmol 2004;15:389-400.

87. Kim SB, Oh SY, Chang MH, Kyung SE. Oculomotor neuromyotonia with lid ptosis on abduction. J AAPOS 2013;17:97-9.

88. McElhinny ER, Reich I, Burt B, et al. Treatment of pseudoptosis secondary to aberrant regeneration of the facial nerve with botulinum toxin type A. Ophthalmic Plast Reconstr Surg 2013;29:175-8.

89. Fagien S. Temporary management of upper lid ptosis, lid malposition, and eyelid fissure asymmetry with botulinum toxin type A. Plast Reconstr Surg 2004;114:1892-902.

90. Scheinfeld $\mathrm{N}$. The use of apraclonidine eyedrops to treat ptosis after the administration of botulinum toxin to the upper face. Dermatol Online J 2005;11:9.

91. Allen RC, Saylor MA, Nerad JA. The current state of ptosis repair: a comparison of internal and external approaches. Curr Opin Ophthalmol 2011;22:394-9.

92. Aakalu VK, Setabutr P. Current ptosis management: a national survey of ASOPRS members. Ophthalmic Plast Reconstr Surg 2011;27:270-6.

93. Fasanella RM, Servat J. Levator resection for minimal ptosis: another simplified operation. Arch Ophthalmol 1961;65:493-6.

94. Lauring L. Blepharoptosis correction with the sutureless Fasanella-Servat operation. Arch Ophthalmol 1977;95:671-4.

95. Beard C. Blepharoptosis repair by modified fasanella-servat operation. Am J Ophthalmol 1970;69:850-7.

96. Fox SA. A modified Fasanella-Servat procedure for ptosis. Arch Ophthalmol 1975;93:639-40.

97. Crawford JS. Repair of blepharoptosis with a modification of the Fasanella-Servat operation. Can J Ophthalmol 1973;8:19-23.

98. Bodian M. A revised Fasanella-Servat ptosis operation. Ann Ophthalmol 1975;7:603-5.

99. Betharia SM, Grover AK, Kalra BR. The Fasanella-Servat operation: a modified simple technique with quantitative approach. $\mathrm{Br} J$ Ophthalmol 1983;67:58-60.

100. North VS, Campbell AA, Callahan AB, Wilcsek G, Kazim M. Enhanced Fasanella-Servat procedure for the graded repair of blepharoptosis. Ophthalmic Plast Reconstr Surg 2017;33:474-6.

101. Pang NK, Newsom RW, Oestreicher JH, Chung HT, Harvey JT. Fasanella-Servat procedure: indications, efficacy, and complications. Can J Ophthalmol 2008;43:84-8.

102. Putterman AM, Urist MJ. Müller muscle-conjunctiva resection. Technique for treatment of blepharoptosis. Arch Ophthalmol 1975;93:619-23.

103. Glatt HJ, Fett DR, Putterman AM. Comparison of $2.5 \%$ and $10 \%$ phenylephrine in the elevation of upper eyelids with ptosis. Ophthalmic Surg 1990;21:173-6. 
104. Baldwin HC, Bhagey J, Khooshabeh R. Open sky Müller muscle-conjunctival resection in phenylephrine test-negative blepharoptosis patients. Ophthalmic Plast Reconstr Surg 2005;21:276-80.

105. Glatt HJ, Putterman AM, Fett DR. Muller's muscle-conjunctival resection procedure in the treatment of ptosis in Horner's syndrome. Ophthalmic Surg 1990;21:93-6.

106. Buckman G, Jakobiec FA, Hyde K, Lisman RD, Hornblass A, Harrison W. Success of the Fasanella-Servat operation independent of Müller's smooth muscle excision. Ophthalmology 1989;96:413-8.

107. Putterman AM, Fett DR. Muller's muscle in the treatment of upper eyelid ptosis: a ten-year study. Ophthalmic Surg 1986;17:354-60.

108. Weinstein GS, Buerger GF. Modifications of the Müller's muscle-conjunctival resection operation for blepharoptosis. Am J Ophthalmol 1982;93:647-51.

109. Perry JD, Kadakia A, Foster JA. A new algorithm for ptosis repair using conjunctival Müllerectomy with or without tarsectomy. Ophthalmic Plast Reconstr Surg 2002;18:426-9.

110. Dresner SC. Further modifications of the Müller's muscle-conjunctival resection procedure for blepharoptosis. Ophthalmic Plast Reconstr Surg 1991;7:114-22.

111. Michels KS, Vagefi MR, Steele E, et al. Müller muscle-conjunctiva resection to correct ptosis in high-risk patients. Ophthalmic Plast Reconstr Surg 2007;23:363-6.

112. Georgescu D, Cole E, Epstein G, et al. Müller muscle-conjunctiva resection for blepharoptosis in patients with glaucoma filtering blebs. Ophthalmic Plast Reconstr Surg 2007;23:285-7.

113. Dailey RA, Saulny SM, Sullivan SA. Müller muscle-conjunctival resection: effect on tear production. Ophthalmic Plast Reconstr Surg 2002;18:421-5.

114. Jones LT, Quickert MH, Wobig JL. The cure of ptosis by aponeurotic repair. Arch Ophthalmol 1975;93:629-34.

115. Anderson RL, Dixon RS. Aponeurotic ptosis surgery. Arch Ophthalmol 1979;97:1123-8.

116. Anderson RL, Beard C. The levator aponeurosis. Attachments and their clinical significance. Arch Ophthalmol 1977;95:1437-41.

117. Lucarelli MJ, Lemke BN. Small incision external levator repair: technique and early results. Am J Ophthalmol 1999;127:637-44.

118. Frueh BR, Musch DC, McDonald HM. Efficacy and efficiency of a small-incision, minimal dissection procedure versus a traditional approach for correcting aponeurotic ptosis. Ophthalmology 2004;111:2158-63.

119. Berlin AJ, Vestal KP. Levator aponeurosis surgery. A retrospective review. Ophthalmology, 1989;96:1033-6; discussion 1037.

120. Brown BZ. Ptosis revision. Int Ophthalmol Clin 1989;29:217-8.

121. Liu D. Ptosis repair by single suture aponeurotic tuck. Ophthalmology 1993;100:251-9.

122. Older JJ. Levator aponeurosis surgery for the correction of acquired ptosis. Ophthalmology 1983;90:1056-9.

123. Waqar S, McMurray C, Madge SN. Transcutaneous blepharoptosis surgery - advancement of levator aponeurosis. Open Ophthalmol J 2010;4:76-80.

124. Shovlin JP. The aponeurotic approach for the correction of blepharoptosis. Int Ophthalmol Clin 1997;37:133-50.

125. McCulley TJ, Kersten RC, Kulwin DR, Feuer WJ. Outcome and influencing factors of external levator palpebrae superioris aponeurosis advancement for blepharoptosis. Ophthalmic Plast Reconstr Surg 2003;19:388-93.

126. Shore JW, Bergin DJ, Garrett SN. Results of blepharoptosis surgery with early postoperative adjustment. Ophthalmology 1990;97:1502-11.

127. Dortzbach RK, Kronish JW. Early revision in the office for adults after unsatisfactory blepharoptosis correction. Am J Ophthalmol 1993;115:68-75.

128. McCord CD, Seify H, Codner MA. Transblepharoplasty ptosis repair: three-step technique. Plast Reconstr Surg 2007;120:1037-44.

129. Mete A, Cagatay HH, Pamukcu C, Kimyon S, Sayg1lı O, Güngör K. Maximal levator muscle resection for primary congenital blepharoptosis with poor levator function. Semin Ophthalmol 2017;32:270-5.

130. Lee JH, Aryasit O, Kim YD, Woo KI, Lee L, Johnson ON 3rd. Maximal levator resection in unilateral congenital ptosis with poor levator function. Br J Ophthalmol 2017;101:740-6.

131. Berke RN. The surgical treatment of congenital ptosis. Trans Pa Acad Ophthalmol Otolaryngol 1961;14:57-61.

132. Beard C. The surgical treatment of blepharoptosis: a quantitative approach. Trans Am Ophthalmol Soc 1966;64:401-87.

133. Cates CA, Tyers AG. Outcomes of anterior levator resection in congenital blepharoptosis. Eye (Lond) 2001;15:770-3.

134. Lee V, Konrad H, Bunce C, Nelson C, Collin JR. Aetiology and surgical treatment of childhood blepharoptosis. Br J Ophthalmol 2002;86:1282-6.

135. Nguyen CT, Hardy TG. Levator resection for congenital ptosis: does pre-operative levator function or degree of ptosis affect successful outcome? Orbit 2017;36:325-30.

136. Carraway JH, Vincent MP. Levator advancement technique for eyelid ptosis. Plast Reconstr Surg 1986;77:394-403.

137. Hylkema HA, Koornneef L. Treatment of ptosis by levator resection with adjustable sutures via the anterior approach. Br J Ophthalmol 1989;73:416-8.

138. Eshraghi B, Ghadimi H. Small-incision levator resection for correction of congenital ptosis: a prospective study. Graefes Arch Clin Exp Ophthalmol 2018;256:1747-50.

139. Allen RC, Jaramillo J, Black R, et al. Clinical characterization and blepharoptosis surgery outcomes in Hispanic New Mexicans with oculopharyngeal muscular dystrophy. Ophthalmic Plast Reconstr Surg 2009;25:103-8.

140. Savino G, Mandarà E, Calandriello L, Dickmann A, Petroni S. A modified one-stage early correction of blepharophimosis syndrome using tutopatch slings. Orbit 2015;34:186-91.

141. Ahn J, Kim NJ, Choung HK, et al. Frontalis sling operation using silicone rod for the correction of ptosis in chronic progressive external ophthalmoplegia. Br J Ophthalmol 2008;92:1685-8. 
142. Bowyer JD, Sullivan TJ. Management of marcus gunn jaw winking synkinesis. Ophthalmic Plast Reconstr Surg 2004;20:92-8.

143. Sakol PJ, Mannor G, Massaro BM. Congenital and acquired blepharoptosis. Curr Opin Ophthalmol 1999;10:335-9.

144. Wasserman BN, Sprunger DT, Helveston EM. Comparison of materials used in frontalis suspension. Arch Ophthalmol 2001;119:687-91.

145. Crawford JS. Repair of ptosis using frontalis muscle and fascia lata: a 20-year review. Ophthalmic Surg 1977;8:31-40.

146. Yoon JS, Lee SY. Long-term functional and cosmetic outcomes after frontalis suspension using autogenous fascia lata for pediatric congenital ptosis. Ophthalmology 2009;116:1405-14.

147. Skaat A, Fabian D, Spierer A, Rosen N, Rosner M, Ben Simon GJ. Congenital ptosis repair-surgical, cosmetic, and functional outcome: a report of 162 cases. Can J Ophthalmol 2013;48:93-8.

148. Lam DS, Ng JS, Cheng GP, Li RT. Autogenous palmaris longus tendon as frontalis suspension material for ptosis correction in children. Am J Ophthalmol 1998;126:109-15.

149. Lam DS, Lam TP, Chen IN, Tsang GH, Gandhi SR. Palmaris longus tendon as a new autogenous material for frontalis suspension surgery in adults. Eye (Lond) 1996;10:38-42.

150. Philandrianos C, Galinier P, Salazard B, Bardot J, Magalon G. Congenital ptosis: Long-term outcome of frontalis suspension using autogenous temporal fascia or fascia lata in children. J Plast Reconstr Aesthet Surg 2010;63:782-6.

151. Wheatcroft SM, Vardy SJ, Tyers AG. Complications of fascia lata harvesting for ptosis surgery. Br J Ophthalmol 1997;81:581-3.

152. Jubbal KT, Kania K, Braun TL, Katowitz WR, Marx DP. Pediatric blepharoptosis. Semin Plast Surg 2017;31:58-64.

153. Esmaeli B, Chung H, Pashby RC. Long-term results of frontalis suspension using irradiated, banked fascia lata. Ophthalmic Plast Reconstr Surg 1998;14:159-63.

154. Wilson ME, Johnson RW. Congenital ptosis. Long-term results of treatment using lyophilized fascia lata for frontalis suspensions. Ophthalmology 1991;98:1234-7.

155. Lamont M, Tyers AG. Silicone sling allows adjustable ptosis correction in children and in adults at risk of corneal exposure. Orbit 2010;29:102-5. 